\title{
STUDI PERENCANAAN PIPA TRANSMISI DALAM PEMANFAATAN SUMBER MATA AIR UMBULAN UNTUK KOTA SURABAYA
}

\author{
Indra Cahya Purnama, Nadjadji Anwar, dan Wasis Wardoyo. \\ Jurusan Teknis Sipil, Fakultas Teknik Sipil dan Perencanaan, Institut Teknologi Sepuluh Nopember (ITS) \\ Jl. Arief Rahman Hakim, Surabaya 60111 Indonesia \\ e-mail: nadjadji@ce.its.ac.id; wasis@ce.its.ac.id
}

\begin{abstract}
Abstrak - Pemerintah Provinsi (pemprov) Jawa Timur berencana untuk memanfaatkan sumber air artesis di Umbulan untuk pemenuhan kebutuhan air bersih masyarakatnya. Air tersebut akan dialirkan melalui pipa ke beberapa daerah, yaitu Umbulan, Kabupaten Pasuruan, Kota Pasuruan, Kabupaten Sidoarjo, Kota Surabaya, dan Kota Gresik.

Pipa yang akan terbentang dari Umbulan hingga Kota Gresik ini akan dibangun oleh Pemprov Jawa Timur. Pemprov Jawa Timur akan menyediakan offtake pada setiap kota yang dilewati pipa tersebut. Selanjutnya Perusahaan Daerah Air Minum (PDAM) masing-masing kota akan mengelola air tersebut dan didistribusikan kepada masyarakat. PDAM Surya Sembada Kota Surabaya direncanakan menerima debit 1000 liter/detik dari proyek ini.

Saat ini Surabaya memiliki enam instalasi penjernihan air untuk memenuhi kebutuhan air bersih warganya. Instalasi tersebut tersebar di dua tempat yaitu tiga unit di Ngagel dan tiga unit di Karang Pilang. Kapasitas dari instalasi tersebut adalah 10.830 liter/detik.

Studi ini dilakukan terhadap pipa transmisi yang akan dibangun oleh PDAM Surya Sembada Kota Surabaya dalam pemanfaatan sumber mata air Umbulan. Analisanya meliputi perhitungan debit kebutuhan air di wialayah rencana pelayanan, dimensi pipa, volume reservoir, pemilihan tipe pompa dan analisa perkiraan biaya untuk membangun pipa
\end{abstract} transmisi tersebut.

Dari hasil studi didapat pipa transmisi yang efisien dalam mengalirkan air umbulan ini adalah pipa steel berdiameter 500 dengan pompa bertekanan 70,23 meter.

Kata Kunci : tekanan, debit, transmisi, pipa.

\section{PENDAHULUAN}

Pemerintah Provinsi (pemprov) Jawa Timur berencana untuk memanfaatkan sumber air artesis di Umbulan untuk pemenuhan kebutuhan air bersih masyarakatnya. Air tersebut akan dialirkan melalui pipa distrisbusi yang akan melewati daerah Umbulan, Kabupaaten Pasuruan, Kota Pasuruan, Kabupaten Sidoarjo, Kota Surabaya, dan Kota Gresik. Dengan program ini diharapkan daerah tersebut dapat terpenuhi kebutuhan air bersihnya secara kualitas, kuantitas, dan kontinyuitas.

Pemprov Jawa Timur akan menyediakan offtake pada setiap kota yang dilewati pipa tersebut. Selanjutnya Perusahaan Daerah Air Minum (PDAM) masing-masing kota akan mengelola air tersebut dan didistribusikan kepada masyarakat. PDAM Surya Sembada Kota Surabaya direncanakan menerima debit 1000 liter/detik dari proyek ini.

PDAM Surya Sembada Kota Surabaya saat ini memiliki instalasi di Ngagel, Karang pilang dan luar kota dengan total kapasitas terpasang sebesar 10.830 liter/detik. Sementara itu cakupan pelayanan hingga Oktober 2014 sudah mencapai $91 \%$.

Pertumbuhan wilayah Barat Surabaya yang sangat cepat sebagai daerah pemukiman, bisnis dan industri diiringi dengan meningkatnya kebutuhan air bersih. Pertumbuhan ini masih akan terus berlangsung mengingat masih banyak lahan yang berpontensi menjadi area perumahan dan perindustrian. Selain itu adanya pembangunan Jalan Lingkar Barat dan Pelabuhan Teluk Lamong akan menjadi katalis dalam perkembangnan di wilayah Surabaya Barat. Untuk itu perlu diadakan studi dalam pemenuhan kebutuhan air bersih di wilayah tersebut dengan memanfaat sumber mata air Umbulan.

Studi yang akan dilakukan adalah terhadap perencanaan pipa transmisi dimana daerah yang akan dilayani air bersihnya dari sumber air umbulan adalah Kelurahan Banjarsugihan, Manukan Wetan, Bibis, Balongsari, Buntaran, Tambak Lagon, Tambak Osowilangon (gambar $1)$. 


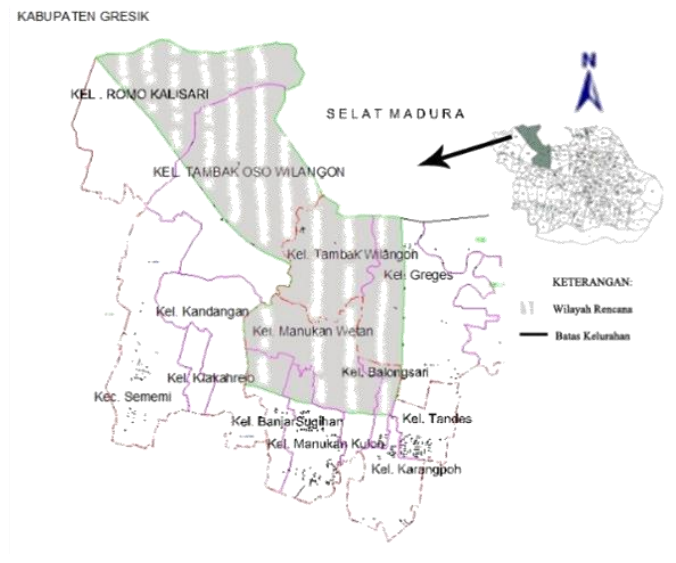

\section{Gambar 1. Peta Daerah Pelayanan Rencana Air Umbulan}

\section{TINJAUAN PUSTAKA}

\section{Aliran dalam Pipa}

Pipa adalah saluran tertutup yang biasanya berpenampang lingkaran dan digunakan untuk menalirkan fluidan dan gas dengan tampang aliran penuh $^{[1]}$. Kehilangan energi pada pipa terbagi menjadi dua yaitu, kehilangan mayor dan minor. Kehilangan mayor disebabkan akibat gesekan antara zat yang pengalir pada pipa dan penampang pipa, sedangkan kehilangan minor terjadi akibat adanya perubahan penampang, belokan dan aksesoris pipa,

\section{Proyeksi Jumlah Penduduk ${ }^{[2]}$}

Analisa Proyeksi Penduduk Metode Linier

Metode ini mengasumsikan pertumbuhan penduduk yang jumlahnya konstan dari tahun ketahun. Model matematisnya adalah sebagai berikut :

$\mathbf{P n}=\mathbf{P o}+\mathbf{n a}$

Dimana:

Pn = Jumlah penduduk pada tahun ke $\mathrm{n}$

Po = Jumlah penduduk pada tahun ke dasar pengamatan

$\mathrm{n}$ = Tambahan tahun terhitung dari tahun dasar

$\mathrm{a}=$ Jumlah pertambahan penduduk tiap tahun

Analisa Proyeksi Metode Bunga Berganda

Metode ini menasumsikan bahwa tingkat pertumbuhan penduduk tiap tahunnya akan selalu proporsional dengan jumlah penduduk tahun sebelumnya. Ada suatu variable yang bersifat konstan, yaitu laju pertumbuhan penduduk, bukan jumlah pertumbuhan penduduk. Model matematisnya adalah sebagai berikut:

$\mathbf{P n}=\mathbf{P o}(\mathbf{1 + r})^{\mathbf{n}}$

Dimana:

$\mathrm{Pn}=$ Jumlah penduduk pada tahun ke $\mathrm{n}$

Po = Jumlah penduduk pada tahun ke dasar pengamatan

$\mathrm{n}$ = Periode pengamatan

$r$ = Persentase laju pertumbuhan tiap tahun

Analisa Proyeksi Metode Regresi Linier

Asumsi dasar penggunaan regresi linier adalah adanya korelasi yang linier antara tahun pengamatan dengan jumlah penduduk dengan pada tahun pengamatan tersebut. Model matematisnya adalah sebagai berikut:

\section{$\mathbf{P}=\mathbf{a}+\mathbf{b x}$}

Dimana:

$\mathrm{P} \quad=$ Jumlah penduduk pada tahun ke $\mathrm{x}$

$\mathrm{x}=$ Tambahan tahun terhitung dari tahun dasar

$\mathrm{a}, \mathrm{b}=$ Konstanta dengan rumus sebagai berikut:

$$
\begin{gathered}
a=\frac{\Sigma P \cdot \Sigma x^{2}-\Sigma x \cdot \Sigma P x}{N \cdot \Sigma x^{2}-(\Sigma x)^{2}} \\
b=\frac{N \cdot \Sigma P x-\Sigma x \cdot \Sigma P}{N \cdot \Sigma x^{2}-(\Sigma x)^{2}}
\end{gathered}
$$

\section{METODOLOGI}

Metode perencanaan disusun untuk mempermudah pelaksanaan studi, guna memperoleh pemecahan masalah sesuai dengan tujuan penelitian yang telah ditetapkan. Dengan prosedur kerja yang sistematis, teratur dan tertib sehingga dapat dipertanggungjawabkan secara ilmiah. 
Perencanaan Pipa Transmisi dalam Pemanfaatan Sumber Mata Air Umbulan untuk Kota Surabaya

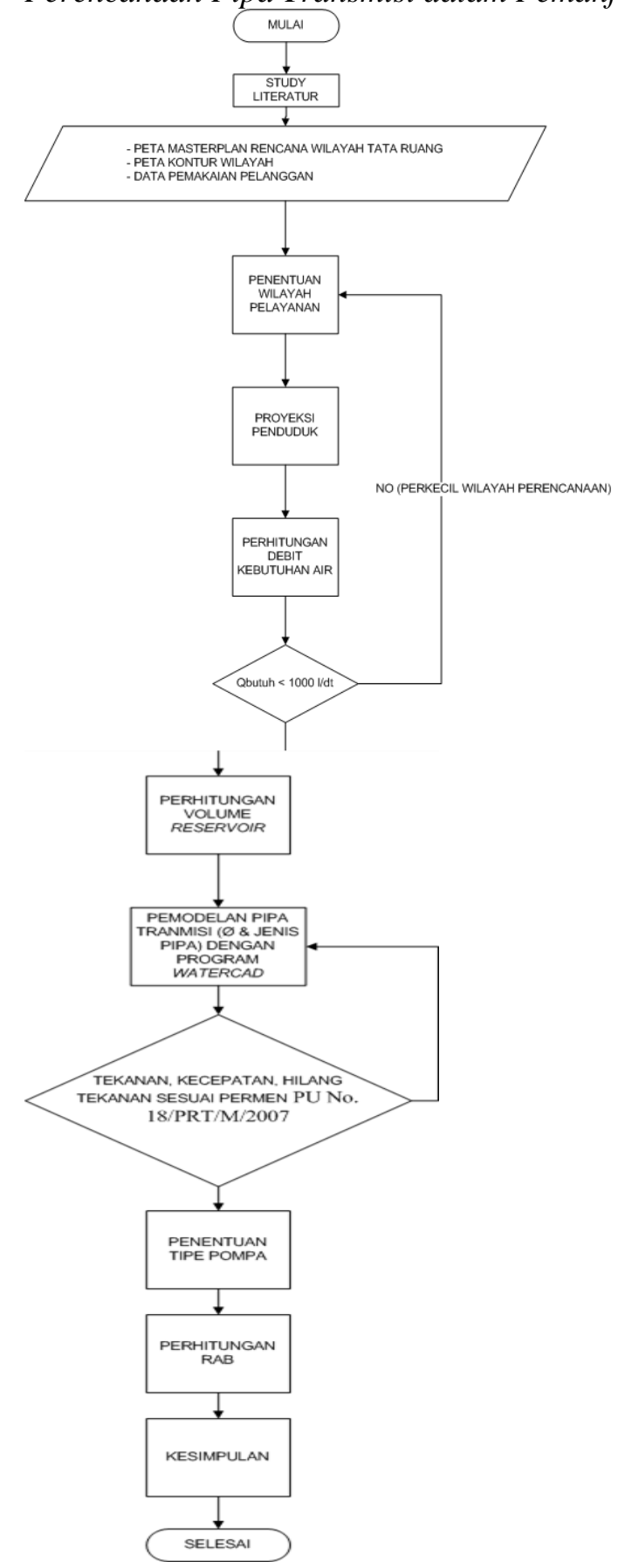

Dari booster pump tersebut pipa akan akan dipasang mengikuti akses jalan yang ada yaitu mulai Jl. Raya Kandangan sampai Jl. Raya Bibis kemudian belok ke Jl. Margomulyo lalu masuk ke reservoir di kompleks pergudangan margomulyo. Peta jalur pipa transmisi dapat dilihat pada gambar 3 .

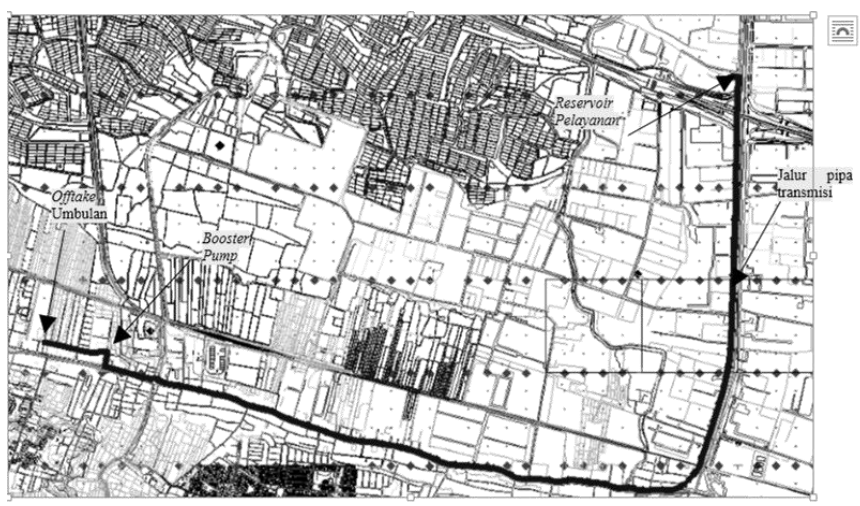

Gambar 3. Jalur Pipa Transmisi

Debit Kebutuhan Air Bersih

Proyeksi Penduduk Wilayah Pelayanan Rencana Proyeksi dilakukan dengan menggunakan data penduduk per kecamatan selama 4 tahun yaitu mulai Tahun 2010 sampai dengân 2013 (Tabel $1)$.

Tabel 1 Jumlah Penduduk per Kelurahan Tahun 2010-2013 pada Daerah Perencanaan

\begin{tabular}{|c|c|c|c|c|c|c|}
\hline Nama Kelurahan & Luas Kelurahan & $\begin{array}{l}\text { Luas Rencana } \\
\text { Pelayanan Dalam } \\
\text { Kelurahan }\end{array}$ & 2010 & 2011 & 2012 & 2013 \\
\hline & $\left(\mathrm{km}^{2}\right)$ & $\left(\mathrm{km}^{2}\right)$ & (orang) & (orang) & (orang) & (orang) \\
\hline \multicolumn{7}{|l|}{ Kecamatan Asemrowo } \\
\hline Tambak Langon & 2.76 & 2.76 & 2,168 & 2,190 & 2,213 & 2,216 \\
\hline Greges & 4.67 & 1.82 & 4,340 & 4,542 & 4,710 & 4,931 \\
\hline \multicolumn{7}{|l|}{ Kecamatan Benowo } \\
\hline Tambak Oso Wilangun & 8.46 & 5.23 & 3,459 & 3,462 & 3,486 & 3,557 \\
\hline Romo Kalisari & 7.58 & 4.08 & 2,127 & 2,220 & 2,313 & 2,383 \\
\hline \multicolumn{7}{|l|}{ Kecamatan Tandes } \\
\hline \begin{tabular}{|l|} 
Balongsari \\
\end{tabular} & 1.25 & 0.44 & 11,765 & 11,933 & 12,178 & - \\
\hline Manukan Wetan & 2.88 & 2.43 & 8,359 & 8,894 & 9,038 & - \\
\hline Manukan Kulon & 2.00 & 0.32 & 35,281 & 35,631 & 35,782 & - \\
\hline Banjarsugihan & 1.02 & 0.58 & 11,872 & 12,131 & 12,263 & - \\
\hline
\end{tabular}

sumber: BPS Kota Surabaya

Akhir

$$
\text { ANALISA DAN PEMBAHASAN }
$$

Berikut tabulasi hasil perkiraan jumlah penduduk dengan ketiga metode proyeksi (Tabel 2).

\section{Jalur Pipa Transmisi}

Jalur pipa transmisi dipilih berdasarkan jalur terpendek dan adanya akses jalan (diusahakan mengikuti jalan yang ada). Sedangkan untuk lokasi reservoir dipilih berdasarkan asset yang dimiliki oleh PDAM yang paling dekat di wilayah tersebut. Dengan mempertimbangkan hal-hal diatas maka dipilih jalur pipa dari offtake di Kandangan. Kemudian air akan masuk ke booster pump yang berada di Jl. Kandangan Jaya. 
Tabel 2 Proyeksi Jumlah Penduduk per Kelurahan di Wilayah Perencanaan pada Tahun 2029

\begin{tabular}{|c|c|c|c|c|}
\hline Nama Kelurahan & $\begin{array}{l}\text { Metode } \\
\text { Linier }\end{array}$ & $\begin{array}{c}\text { Metode Bunga } \\
\text { Berganda }\end{array}$ & $\begin{array}{l}\text { Metode Regersi } \\
\text { Linier }\end{array}$ & Maksimum \\
\hline & (orang) & (orang) & (orang) & (orang) \\
\hline \multicolumn{5}{|l|}{ Kecamatan Asemrowo } \\
\hline Tambak Langon & 2472 & 2491 & 2489 & 2491 \\
\hline Greges & 8083 & 9744 & 8028 & 9744 \\
\hline \multicolumn{5}{|l|}{ Kecamatan Benowo } \\
\hline \begin{tabular}{|l|} 
Tambak Oso Wilangun \\
\end{tabular} & 4080 & 4131 & 4048 & 4131 \\
\hline Romo Kalisari & 3748 & 4370 & 3768 & 4370 \\
\hline & & & & \\
\hline \multicolumn{5}{|l|}{ Kecamatan Tandes } \\
\hline Balongsari & 15689 & 16330 & 15676 & 16330 \\
\hline Manukan Wetan & 14810 & 17642 & 14875 & 17642 \\
\hline Manukan Kulon & 40041 & 40341 & 40074 & 40341 \\
\hline Banjarsugihan & 15587 & 16156 & 15608 & 16156 \\
\hline
\end{tabular}

Karena tidak seluruh wilayah kelurahan merupakan daerah pelayanan rencana Air Umbulan, maka untuk mendapatkan proyeksi jumlah penduduk di Tahun 2029, dihitung secara proporsional berdasarkan luas kelurahan di daerah pelayanan (Tabel 3). Dari hasil perhitungan didapat total penduduk di wilayah pelayanan rencana adalah 47488 jiwa.

Tabel 3 Perhitungan Jumlah Penduduk di Daerah Pelayanan Air Umbulan

\begin{tabular}{|c|c|c|c|c|c|}
\hline Nama Kelurahan & $\begin{array}{c}\text { Luas } \\
\text { Kelurahan }\end{array}$ & $\begin{array}{l}\text { Luas Daerah } \\
\text { Pelayanan } \\
\text { Dalam } \\
\text { Kelurahan }\end{array}$ & Persentase & $\begin{array}{c}\text { Proyeksi } \\
\text { Penduduk } \\
\text { Tahun } 2029\end{array}$ & $\begin{array}{c}\text { Jumlah } \\
\text { Penduduk di } \\
\text { Daerah } \\
\text { Rencana }\end{array}$ \\
\hline & $\left(\mathrm{km}^{2}\right)$ & $\left(\mathrm{km}^{2}\right)$ & (\%) & & (orang) \\
\hline \multicolumn{6}{|l|}{ Kecamatan Asemrowo } \\
\hline \begin{tabular}{|l|} 
Tambak Langon \\
\end{tabular} & 2.76 & 2.76 & 100.00 & 2,491 & 2,491 \\
\hline Greges & 4.67 & 1.82 & 38.97 & 9,744 & 3,797 \\
\hline \multicolumn{6}{|l|}{ Kecamatan Benowo } \\
\hline \begin{tabular}{|l|} 
Tambak Oso Wilangun \\
\end{tabular} & 8.46 & 5.23 & 61.82 & 4,131 & 2,554 \\
\hline Romo Kalisari & 7.58 & 4.08 & 53.83 & 4,370 & 2,352 \\
\hline \multicolumn{6}{|l|}{ Kecamatan Tandes } \\
\hline Balongsari & 1.25 & 0.44 & 35.20 & 16,330 & 5,748 \\
\hline Manukan Wetan & 2.88 & 2.43 & 84.48 & 17,642 & 14,904 \\
\hline Manukan Kulon & 2.00 & 0.32 & 16.00 & 40,341 & 6,455 \\
\hline \multirow[t]{2}{*}{ Banjarsugihan } & 1.02 & 0.58 & 56.86 & 16,156 & 9,187 \\
\hline & & & & Jumlah & 47,488 \\
\hline
\end{tabular}

\section{Debit Kebutuhan Rencana}

Dengan jumlah penduduk 47.488 orang, maka wilayah pelayanan termasuk dalam kategori kota kecil. Kriteria tersebut mengacu pada Petunjuk Teknis Rencana Induk dan Studi Kelayakan Sistem Penyedia Air Minum, DPU Dirjen Cipta Karya, 1998. Dengan kriteria tersebut didapat debit kebutuhan air bersih di wilayah perencanaan adalah 269,69 liter/detik.

\section{Debit di Dalam Pipa Transmisi dan Volume Resevoir}

Debit yang mengalir di dalam pipa transmisi direncanakan tetap, sedangkan debit pemakaian berfluktuasi. Ketika debit pemakaian lebih kecil dari debit di pipa transmisi, maka reservoir akan terisi. Sedangkan saat debit pemakaian lebih besar dari debit di pipa transmisi, maka volume reservoir akan terkuras (terpakai).

Reservoir yang efisien adalah reservoir yang memiliki nilai selisih volume pengisian dan pemakaian sama dengan nol. Variabel yang dapat diubah untuk mencapai hal tersebut adalah debit pada pipa transmisi. Maka dilakukan trial $n$ error pada debit pipa transmisi agar tercapai volume reservoir yang efisien.

Dari analisa didapat debit pada pipa transmisi adalah 280,27 liter/detik dan volume reservoir sebesar 2.236,82 $\mathrm{m}^{3}$ (termasuk volume mati). Berikut grafik kinerja reservoir antara debit pemakaian (outflow) dan debit pada pipa transmisi (Inflow).

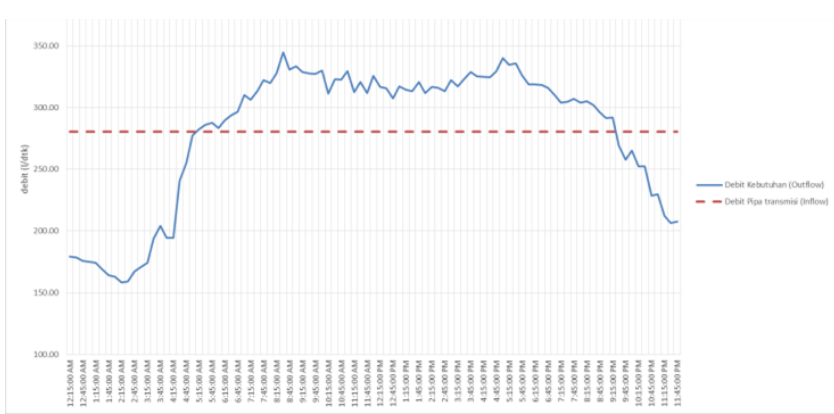

\section{Gambar 4. Kinerja Reservoir di Wilayah} Rencana

Pemodelan Pipa Transmisi dengan Program Watercad

Pemodelan dilakukan sesuai dengan Permen PU No. 18/PRT/M/2007 pada tabel kriteria pipa transmisi, yaitu dengan pipa PVC $(\varnothing 300$ dan $\varnothing 400)$ dan DCI $(\varnothing 300, \varnothing 400, \varnothing 500, \varnothing 600$ dan $\varnothing 800)$. Namun karena pipa DCI sulit didapatkan maka material tersebut diganri dengan pipa steel. Berikut hasil analisa hidrolika 7 pemodelan yang telah ditentukan dengan asumsi pompa awal memiliki tekanan sebesar $30 \mathrm{~m}$.

\section{Tabel 4 Hasil Analisa Pemodelan Pipa} Transmisi

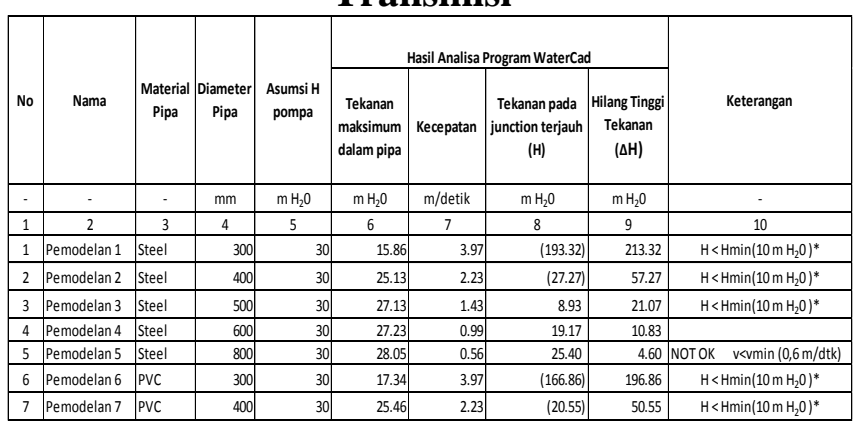

Dalam pemodelan awal, yang pertama diperhatikan adalah kecepatan aliran dalam pipa. 
Perencanaan Pipa Transmisi dalam Pemanfaatan Sumber Mata Air Umbulan untuk Kota Surabaya

Jika kecepatannya diluar dari kriteria pipa transmisi, maka pemodelan tidak dapat diguanakan. Pada tabel di atas dapat dilihat kecepatan aliran pada pipa steel $\varnothing 800$ lebih kecil dari kecepatan minimum yaitu 0,6 meter/detik. Maka Pemodelan tersebut tereleminasi.

Yang kedua adalah total hilang tekanan. Permen PU No. 18/PRT/M/2007 mengatur hilang tinggi tekanan maksimal adalah $30 \%$ dari tekanan pompa. Maka dibuat pemodelan sesuai kriteria tersebut dan didapat hasilnya pada tabel 5 .

\section{Tabel 5 Hasil Analisa Pemodelan Pipa Transmisi dengan Pompa yang telah} Disesuaikan

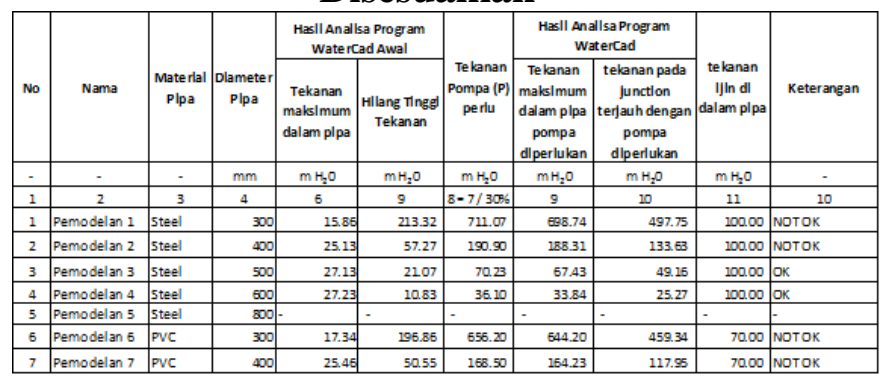

Dari hasil tersebut didapakan pemodelan yang dapat diguanakan pada pipa transmisi ini pipa adalah dengan material steel dan berdiameter 500 dan 600 .

\section{Tipe Pompa}

Dalam studi kali ini direncanakan menggunakan pompa booster merk Grundfos dengan spesifikasi sebagai berikut:

Tabel 6. Spesifikasi Pompa Booster yang Dibutuhkan

\begin{tabular}{|c|c|c|c|c|c|c|}
\hline No & Nama & $\begin{array}{c}\text { Material } \\
\text { Pipa }\end{array}$ & $\begin{array}{c}\text { Diameter } \\
\text { Pipa }\end{array}$ & Q & $\begin{array}{c}\text { Tekanan } \\
\text { Pompa } \\
\text { (Hf) perlu }\end{array}$ & Tipe Pompa \\
\hline- & - & - & $\mathrm{mm}$ & $\mathrm{m}^{3} /$ detik & $\mathrm{m} \mathrm{H}_{2} 0$ & \\
\hline 1 & 2 & 3 & 4 & 5 & 6 & 7 \\
\hline 1 & Pemodelan 3 & steel & 500 & 0.094 & 70.23 & NK-150-400/343 \\
\hline 2 & Pemodelan 4 & steel & 600 & 0.094 & 36.10 & NK-150-315/338 \\
\hline
\end{tabular}

Pada tabel 6 terdapat tipe pompa Grundfos yang didapat berdasarkan grafik pompa dari pabrik pompa tersebut.

\section{Volume dan RAB}

Selanjutnya kedua pemodelan tersebut dibangingkan dari segi ekonomi. Tujuannya sebagai salah satu pertimbangan dalam mengambil keputusan.

Berikut perbandingan biaya total dari kedua pemodelan.
Tabel 7. Hasil Analisa Pemodelan Pipa Transmisi

\begin{tabular}{|l|r|r|}
\hline \multirow{2}{*}{ Nama Pekerjaan } & \multicolumn{2}{|c|}{ Nilai } \\
\cline { 2 - 3 } & \multicolumn{1}{|c|}{ Opsi 1 } & \multicolumn{1}{c|}{ Opsi 2 } \\
\hline & \multicolumn{1}{c|}{ (Rp.) } & \multicolumn{1}{c|}{ (Rp.) } \\
\hline Reservoir & $6,941,435,200$ & \multicolumn{1}{c|}{$6,941,435,200$} \\
\hline Material dan Aksesoris & $8,079, \mathbf{4 6 1 , 3 6 6}$ & $11,171,247,080$ \\
\hline Galian dan Rekondisi & $10,389,280,201$ & $11,300,981,128$ \\
\hline Pompa & $1,485,413,645$ & $1,738,663,960$ \\
\hline Jembatan Pipa & $299,000,762$ & $299,000,762$ \\
\hline \hline Total & $\mathbf{2 7 , 1 9 4 , 5 9 1 , 1 7 4}$ & $\mathbf{3 1 , 4 5 1 , 3 2 8 , 1 3 0}$ \\
\hline
\end{tabular}

Dari tabel 7 didapat nilai investasi yang lebih kecil yaitu dengan membangunan pipa transmisi dengan material steel berdiameter $500 \mathrm{~mm}$.

\section{KESIMPULAN}

Berdasarkan hasil analisa yang telah dilakukan, didapat kesimpulan sebagai berikut:

1. Berdasarkan peta pelayanan PDAM Kota Surabaya, wilayah yang akan dilayani dari proyek umbulan ini adalah sub zona 424, 425, 429, 430, daan 431.

2. Debit kebutuhan air di daerah rencana pelayanan air umbulan adalah 269.69 1/detik.

3. Air akan dialiri melalui pipa transmisi yang akan dibangun dari rumah pompa kandangan melawati Jl. Raya Tandes kemudian masuk ke Jl. Margomulyo hingga masuk ke reservoir di Margomulyo.

4. Pipa transmisi yang efisien untuk mengalirkan air umbulan ini adalah Pipa Steel berdiameter $500 \mathrm{~mm}$

5. Volume reservoir yang dibutuhkan untuk dapat melayani wilayah perencanaan adalah $2.236,82 \mathrm{~m}^{3}$.

6. Pompa yang dibutuhkan adalah 4 unit ( $3 O N$; $1 O F F$ ) dengan debit masing-masing pompa 94 liter/detik dan tekanan 70,23 m.

7. Dari sisi ekonomi, pemodelan yang nilai pekerjaannya termurah pemodelan 3 , yaitu dengan material steel diameter $500 \mathrm{~mm}$ dengan nilai pembangunan Rp.25.269.896.532,-.

\section{DAFTAR PUSTAKA}

[1] Triatmodjo, B. (1993). Hidraulika II. Yogyakarta: Beta Offset.

[2] PERMEN PU NO. 18/PRT/M/2007. (2007). Penyelenggaraan Pengembangan Sistem Penyedia Air Minum. Jakarta. 